\title{
Scar Endometriosis-An Incidental Fine Needle Aspiration Cytology Finding
}

\author{
Natarajan S, Bheema R, Hemalatha G and Bupesh G* \\ Department of Pathology \& Research \& Development Wing, Sree Balaji Medical \\ College \& Hospital (SBMCH), India \\ *Corresponding author: G Bupesh, Department of Pathology \& Research \& \\ Development Wing, Sree Balaji Medical College \& Hospital (SBMCH), Chromepet, \\ Chennai-600044, India, Email: bupeshgiri55@gmail.com
}

\section{Mini Review \\ Volume 3 Issue 1}

Received Date: December 11, 2018

Published Date: January 25, 2019

DOI: $10.23880 / \mathrm{mjccs}-16000199$

\section{Abstract}

Endometriosis is the presence of endometrial glands and stroma outside their normal intrauterine location. Exrauterine implants have been noted in abdomen, axial and peripheral skeleton, lungs and pelvic diaphragm, peritoneum. Endometriosis may spread to sites of surgical abdominal incisions such as previous caesarean sections, laparoscopy, and hernia repair. These abdominal endometriosis accounts for $0.5 \%-1 \%$ of all pelvic endometriosis. We present a case of 26 year old lady presenting with nodule in the previous caesarean scar region.

Key words: Abdominal wall; Scar Endometriosis; FNAC; Laparascopy; Caesarean section

\section{Introduction}

26 Year old lady presented with a swelling over the previous Caesarean scar region progressively increasing in size for the past 1 year. She also complained of cyclical pain during menstruation for past 3 months. On Examination- Deep seated tender nodule measuring 1x1 $\mathrm{cm}$ firm, mobile was present over the caeserian scar region Ultrasound abdomen showed a hypoechoic lesion just below LSCS scar region [1-3].

\section{Cytology}

Fine Needle Aspiration Cytology was done. Smears were fixed in 95\% ethyl alcohol and stained with hematoxylin and eosin stain and which revealed cohesive clusters of epithelial cells showing uniform small cells having bland chromatin with scanty cytoplasm in a clean background and Scar endometriosis was diagnosed.
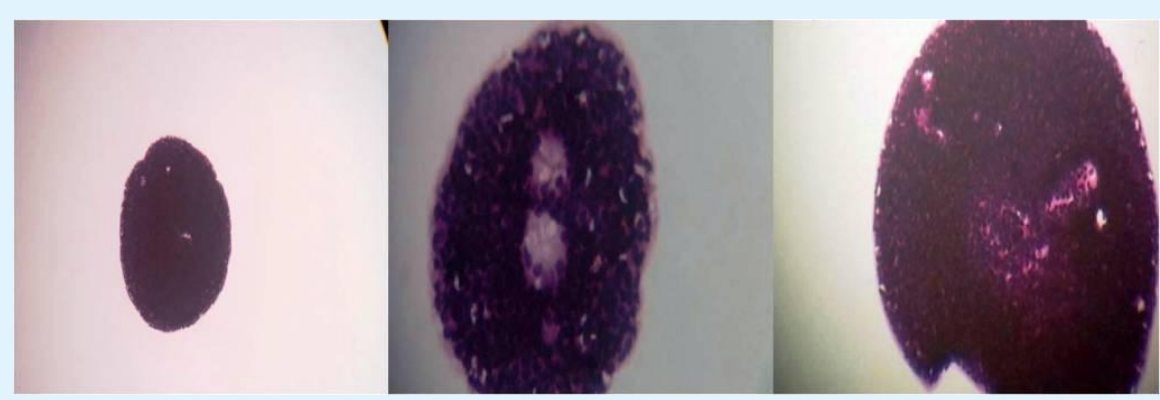

Figure 1: Paucicellular smear shows an occasional cluster of tightly cohesive endometrial cells and stroma. (40x, scanner view, 100x low power view) 


\section{Medical Journal of Clinical Trials \& Case Studies}

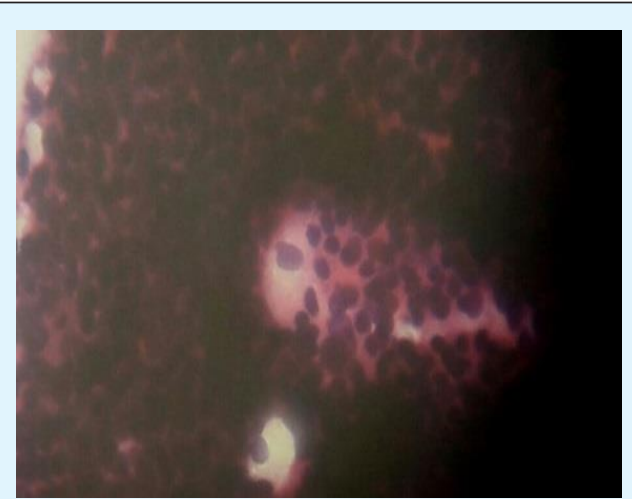

Figure 2: Smear showing endometrial cells with small uniform cells bland chromatin and scanty cytoplasm. (400x, high power)

\section{Discussion}

Endometriosis was first described by Rokitansky in 1860 [3]. Endometriosis is defined as ectopic growth of endometrial gland and stroma outside the uterus causing infertility, pelvic pain, and menstrual abnormalities [4]. Predominant locations are pelvis, ovaries, Douglas pouch, uterine ligament, rectovaginal septum and cervix. Endometriosis occurring in the abdominal wall also known as endometriomais a rare entity and was first described by Meyer in 1903. This condition should kept in mind when encountering an painful nodule in a parous woman following a gynaecological or obstetric surgery as this can be can be confused with incisional hernia suture granuloma, abscess or lipoma. This commonly occurs near the previous caesarean scar regionhysterotomy.

The incidence of endometriosis following a cesearean section is $0.08 \%$. Scar endometriosis has also been reported in scars following hysterectomy, tubal ligation, ectopic pregnancy, episiotomy, inguinal herniorrhaphy. The most possible explanation seems to be direct mechanical implantation of endometrial tissue into the wound during caesarean section and subsequent stimulation by estrogen. Smears from endometriomas show varying cellularity consisting of epithelial cells, stromal cells, macrophages and inflammatory cells. The presence of any two out of three components on cytology is enough to diagnose endometrioma. The cytological features vary according to cyclical hormonal changes during menstruation. In proliferative phase the epithelial cells form a cohesive cluster of uniform small cells with scant cytoplasm, round to ovoid nuclei with bland chromatin.

In the secretory phase cell size increases with cytoplasmic microvacoulations .The stromal cells show abundant cytoplasm and predecidual changes.The lesions which are included in the differential diagnosis are metastatic nodule, suture granuloma, and nodular fasciitis [5]. Smears from metastatic malignant lesions are hypercellular with neoplastic cells. Suture granuloma shows inflammatory cells with the presence of granulomas. Nodular fasciitis show myxoid background and pleomorphic cells.

\section{Conclusion}

Endometriosis in a scar tissue presents as nodule and is often confused with suture granuloma, abscess, lipoma, incisional hernia or metastatic malignancy. Fine Needle Aspiration Cytology is an easy and economical method to diagnose this rare entity. This case is presented because of its rare presentation difficulty in diagnosis, and to avoid the pitfalls of misdiagnosis.

\section{References}

1. Carlo Bulletti, Maria Elisabetta Coccia, Silvia Battistoni, Andrea Borini (2010) Endometriosis and infertility. J Assist Reprod Genet 27(8): 441-447.

2. Geeta Pachori, Rashmi Sharma, Ravi Kant Sunaria, Tushar Bayla (2015) Scar endometriosis: Diagnosis by fine needle aspiration. J Cytol 32(1): 65-67.

3. A History of Endometriosis (2011), Ronald E Batt (Ed.), pp: 1-12.

4. Roncoroni L, Costi R, Violi V, Nunziata R (2001) Endometriosis on laparotomy scar: a three-case report. Arch Gynecol Obstet 265(3): 165-167.

5. Blanco RG, Parithivel VS, Shah AK, Gumbs MA, Schein $M$, et al. (2003) Abdominal wall endometriomas. Am J Surg 185(6): 596-598. 